\title{
Situation types in complementation: Oromo attitude predication*
}

\author{
Shannon Bryant \\ Harvard University
}

\author{
Diti Bhadra \\ University of Minnesota
}

\begin{abstract}
Though languages show rich variation in the embedding strategies employed in attitude reports, most mainstream semantic theories of attitudes assume that the clausal complement of an attitude verb contributes at least a proposition to the composition. The goal of this paper is to add to the growing cross-linguistic perspective on attitudes by providing semantic analyses for the two embedding strategies found with attitude verbs in Oromo (Cushitic): verbal nominalization and embedding under $a k k a$ 'as'. We argue that Oromo exemplifies a system in which non-speech attitudes uniformly embed situations rather than propositions, thereby expanding the empirical landscape of attitudes in two ways: (a) situations and propositions are both ontological primitives used in the expression of attitudes, and (b) attitude verbs in languages like Oromo do the semantic heavy lifting, contributing the "proposition" to propositional attitudes.
\end{abstract}

Keywords: Oromo, complementation, attitudes, verbal nominalization, situation types

\section{Introduction}

Decades of work on the syntax of clausal complementation have revealed rich variation in the embedding strategies employed across languages in the expression of attitudes. Only lately has focus within formal semantics turned to better understanding the variety of ways in which the basic semantic components of an attitude report are contributed to the structure. The standard theoretical take, following Hintikka's (1969) classic analysis, is that the clausal complement of an attitude verb contributes a proposition (type $<w t^{1}$ ) to the semantics, while the verb introduces modal quantification along with the attitude flavor. A recent theoretical

* We are very grateful for the Oromo speakers we worked with, Beekan Erena and Ebisie Deressa. We also thank the audiences of SALT30, Eco5 2020, and Harvard Meaning \& Modality Lab, as well as Kate Davidson, Claire Halpert, Lucas Champollion, Isabelle Charnavel, and Ken Safir for their input and feedback.

1 Within the Hintikkan tradition, propositions as modeled as unstructured sets of possible worlds. Note that we distinguish worlds (type $w$ ) from situations (type $s$ ) in the present work. 


\begin{tabular}{|l|c|c|c|c|}
\hline & Bogal-Allbritten & Kratzer/Moulton & Hintikka & $? ?$ \\
\hline $\begin{array}{l}\text { Proposition } \\
\text { contributed by: }\end{array}$ & Complement & Complement & Complement & Verb \\
\hline $\begin{array}{l}\text { Quantification } \\
\text { contributed by: }\end{array}$ & Complement & Complement & Verb & Verb \\
\hline $\begin{array}{l}\text { Attitude flavor } \\
\text { contributed by: }\end{array}$ & Complement & Verb & Verb & Verb \\
\hline
\end{tabular}

Table 1 The landscape of attitude reports, with typological gap

camp (e.g., Moulton 2015; Elliot 2016; Kratzer 2016; Deal 2017; Hanink \& Bochnak 2017) argues for several languages that the embedded clause carries more semantic weight in attitude reports than is assumed within the Hintikkan tradition; in particular, they attribute the introduction of modal quantification to functional material within the embedded clause rather than the embedding verb. BogalAllbritten (2016) presents Navajo attitude reports with nisin as a limiting case in the landscape of attitudes, where even the attitude flavor is contributed by the complement. As shown in Table 1, these three perspectives together capture different ways in which the key components of an attitude-proposition, modal quantification, and attitude flavor - can be packaged in an attitude verb and its clausal complement. However, within each of these existing accounts, the clausal complement contributes at least a proposition. This leaves a gap in the typological picture: even taking for granted that propositions are necessary ingredients to attitude reports, we would expect to find attitude reports that fall on the opposite end of the spectrum from nisin reports, such that all of the semantic heavy-lifting falls to the embedding verb.

In this paper, we aim to fill out the expanded landscape in Table 1 by exploring the composition of non-speech attitude reports in Oromo (Lowland East Cushitic). Two embedding strategies are found with Oromo attitudes: verbal nominalization with subject and embedding under the particle $a k k a$ 'as', exemplified in (1) and (2), respectively. $^{2}$

$$
\begin{array}{llll}
\text { gammachuu-n } & {[\text { dachaasaa-n }} & \text { raf-aa } & \text { jiraacc-uu=saa]-tti } \\
\text { Gam.-NOM } & {[\text { Dac.-NOM }} & \text { sleep-CVB } & \text { exist-NMLZ=POSS.3sm]-LOC }
\end{array}
$$

2 Except where otherwise indicated, data presented in this paper were elicited from an adult male native speaker of Wollega Oromo, a variety of Oromo spoken in West-Central Ethiopia. Elicitations were conducted in person at Harvard University as part of coursework for Ling 117r: Linguistic Field Methods (Spring 2018), and continued personal elicitations were conducted over the summer and fall of 2018 in Cambridge, Massachusetts. Additional confirmation of the data was done in person with one adult female native speaker of Wollega Oromo in Minneapolis, Minnesota. 
Situation Types in Complementation

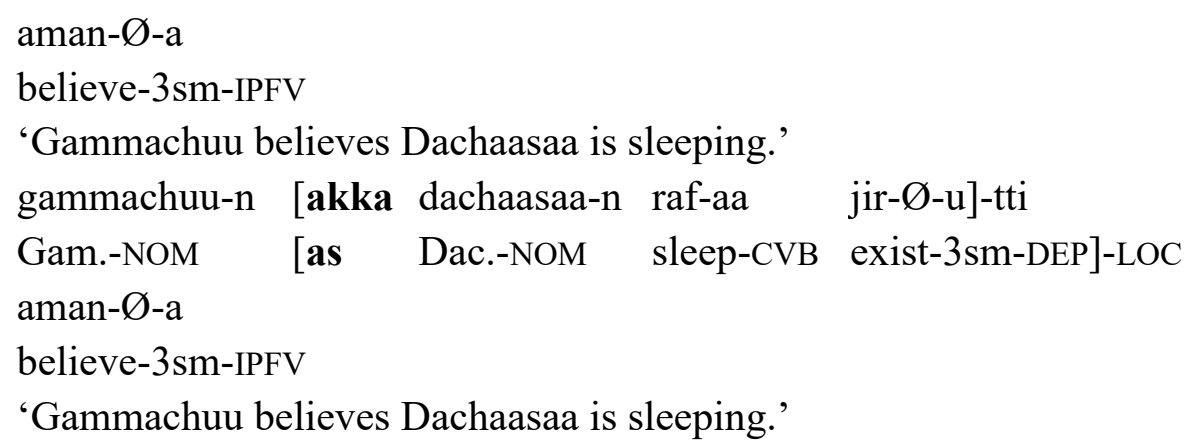

As the paraphrases indicate, both embedding strategies give rise to attitude reports with truth conditions comparable to their English counterparts. However, we propose that the semantic building blocks are bundled much differently in Oromo.

We adopt the view from work at the syntax-semantics interface that the size of an embedded clause determines the semantic object picked out by that clause. In particular, we assume the architecture put forth by Ramchand and Svenonius (2014), according to which the three major clausal domains - $\mathrm{V}, \mathrm{T}$, and $\mathrm{C}-$ correspond to three distinct sorts in natural language ontology-events, situations, and propositions (see Figure 1). Crucially, we argue that the clausal complements of Oromo attitudes, whether verbal nominalizations or $a k k a$ constructions, contain maximal verbal projections belonging to the $\mathrm{T}$-domain rather than the $\mathrm{C}$-domain; hence, they contribute a situation to the semantics rather than a proposition. Oromo thus exemplifies a system that fills the gap in the typology of propositional attitudes and calls for a new sort of formal analysis.

This paper is organized as follows: in Section 2 we offer further introduction to the interface assumptions that undergird this project, along with motivation for extension to Oromo. We then take a closer look at the structure and distribution of the clausal complements of Oromo non-speech attitude verbs in Section 3. Based on these data, we conclude that Oromo attitudes embed situations rather than propositions, and in Section 4 we offer a novel formal analysis that is able to capture the Oromo system. We conclude in Section 5.

\section{The syntax-semantics interface of clausal embedding}

It has long been the prevailing view within generative syntax that the clausal spine consists of three major, hierarchically ordered domains (Chomsky 1981, 1986, 1995; Pollock 1989; Platzack 2000; Grohmann 2003; i.a.). Though labels for these domains vary across authors, here we will refer to them as the V(erb) domain, $\mathrm{T}(\mathrm{ense})$ domain, and C(omplementizer) domain, as in Figure 1. Ramchand and Svenonius (2014) provide a semantically grounded account of this core hierarchy, according to which the tripartition of the clause tracks with a three-way distinction 
SYNTACTIC DOMAIN

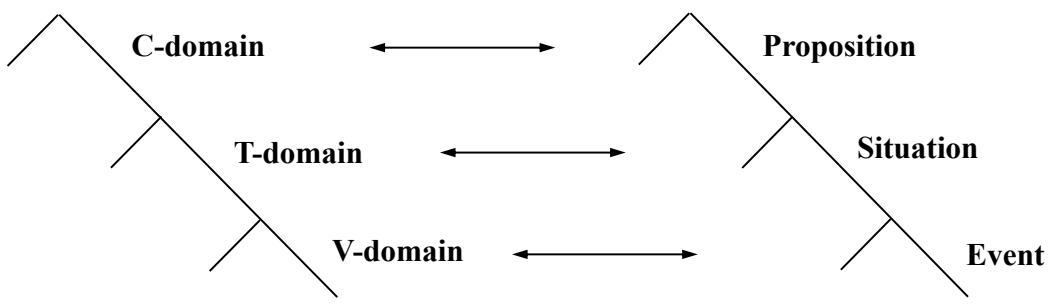

Figure 1 Correspondence between syntactic domains and semantic objects

in the conceptual primitives underpinning composition. We summarize this framework as follows: ${ }^{3}$

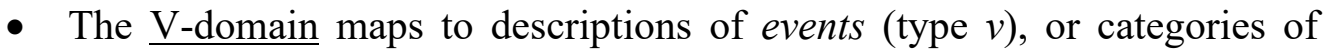
eventualities, which lack spatiotemporal parameters as well as speakeroriented parameters.

- The T-domain maps to descriptions of situations (type $s$ ), or individual eventualities, which permit spatiotemporal specification but which lack speaker-oriented parameters, most importantly modal anchoring.

- The $\mathrm{C}$-domain maps to descriptions of propositions (type $p$ ), or contentful objects that include speaker-oriented parameters like modal anchoring.

In their forthcoming paper, Wurmbrand and Lohninger (submitted) integrate Ramchand and Svenonius's (2014) perspective into a cross-linguistic study of clausal complementation. Based on structural evidence such as clitic climbing and the expression of tense and aspect, ${ }^{4}$ they argue that languages distinguish up to three broad, semantically-defined categories of clausal complements. These, too, are labeled as event, situation, and proposition, reflecting the sort of semantic object picked out by clauses belonging to each category. Under this proposal, clausal embedding is crucially sensitive to the semantic contribution of the complement clause: for example, a predicate that selects for a situation may nevertheless be compatible with a CP complement, as long as that complement lacks the functional projection responsible for the transition from situations to propositions.

Here we extend the insights of Ramchand and Svenonius (2014) and Wurmbrand and Lohninger (submitted) to Oromo. In Oromo, three categories of

3 We depart somewhat from the descriptions provided by Ramchand and Svenonius (2014) and later by Wurmbrand and Lohninger (submitted). However, we believe that the core insights of these authors remain intact.

4 Wurmbrand and Lohninger (submitted) consider evidence from Greek, Bulgarian, Buryat, Serbian, Croatian, Bosnian, Slovenian, Romanian, English, Italian, Czech, and Brazilian Portuguese. 
embedded clauses are distinguished by their structure, distribution, and meaning contribution. One category is exemplified by the embedding strategies in both (1) and (2), that is, verbal nominalization with subject (henceforth VNS) and embedding under $a k k a$ 'as'. In addition to non-factive epistemic attitude verbs, these two strategies also occur alongside factive epistemic attitude verbs like beek'know' and yaadat- 'remember'; emotive attitude verbs like abdaD- 'hope', barbaD- 'want', and gammadaadha 'be happy (that)'; perception verbs like dhaga'- 'hear' and arg- 'see'; and other-manipulation verbs like gaafat- 'ask (to)', himm- 'tell (to)', and goD- 'make/force (to)' (Gragg 1976; Owens 1985; Baye 1986; Dubinsky, Lloret \& Newman 1988; Alemaheyu 2015). Semantically speaking, the distribution of predicates that are compatible with VNS and akka embedding is rather wide; it is worth noting already that emotives and othermanipulation verbs are frequently found with non-propositional complements across languages (see Wurmbrand \& Lohninger submitted).

VNS and akka embedding are not the only embedding strategies found in Oromo. Complements of a second category appear alongside speech verbs like jedh- 'say' and labsaD- 'announce', as shown in example (3) (Owens 1985). Note in (3) that clauses of this category, which we take to be full CPs and, hence, the syntactically largest embedded clauses found in Oromo, ${ }^{5}$ cannot occur with attitude verbs that do not express a speech event, including aman- 'believe'.
a. gammachuu-n
[an-i raf-aa
jir- $\varnothing$-a]
jedh-Ø-e
Gam.-NOM [1s-NOM sleep-CVB exist-3sm-IPFV] say-3sm-PFV

'Gammachuu said that I(=speaker) am sleeping.'
b. *gam.-n
[an-i
raf-aa
jir-Ø-a]
aman-Ø-a
Gam.-NOM [1s-NOM sleep-CVB exist-3sm-IPFV]
believe-3sm-IPFV

Intended: 'Gammachuu believes I am sleeping.'

The third complement category is found only with verbs of self-inducement, including attempt verbs like jaal- 'try' and aspectual verbs like fit'- 'finish' (Owens 1985; Mazengia 2015). Clauses of this category are syntactically encoded as verbal nominalizations without subjects: as illustrated in (4), subjects are not permitted in these complements, even if coreferent with the matrix subject.
gammachuu-n
$[$ raf-uu-f $(*=$ saa $)]$
jaal-aa jir-Ø-a
Gam.-NOM
[sleep-NMLZ-DAT $(*=$ POSS. $3 \mathrm{sm})]$
say-CVB
exist-3sm-IPFV
'Gammachuu is trying to sleep.'

\footnotetext{
5 This claim, for which we provide some evidence in Section 3.2, is consistent with the crosslinguistic generalization that speech verbs embed the largest complements available in the language (Givón 1980; see also Deal 2017 and references therein).
} 


\begin{tabular}{|l|c|c|c|c|c|}
\hline \multicolumn{1}{|c|}{ Verb type } & speech & $\begin{array}{c}\text { epistemic } \\
\text { attitude }\end{array}$ & $\begin{array}{c}\text { emotive } \\
\text { attitude }\end{array}$ & $\begin{array}{c}\text { other- } \\
\text { manipulation }\end{array}$ & $\begin{array}{c}\text { self- } \\
\text { inducement }\end{array}$ \\
\hline Example & jedh- 'say' & $\begin{array}{c}\text { aman- } \\
\text { 'believe' }\end{array}$ & $\begin{array}{c}a b d a D- \\
\text { 'hope' }\end{array}$ & goD- 'make' & jaal- 'try' \\
\hline $\begin{array}{l}\text { Embedding } \\
\text { strategy }\end{array}$ & full clause & \multicolumn{2}{|c|}{$\begin{array}{c}\text { verbal nominalization w/ subject } \\
\text { akka-embedding }\end{array}$} & $\begin{array}{c}\text { V.n. w/o } \\
\text { subject }\end{array}$ \\
\hline $\begin{array}{l}\text { Minimal } \\
\text { structure }\end{array}$ & C-domain & \multicolumn{3}{|c|}{ T-domain } & V-domain \\
\hline $\begin{array}{l}\text { Semantic } \\
\text { category }\end{array}$ & Proposition & \multicolumn{3}{|c|}{ Situation } & Event \\
\hline $\begin{array}{l}\text { W\&L } \\
\text { distribution }\end{array}$ & \multicolumn{2}{|c|}{ Proposition } & Situation & Event \\
\hline
\end{tabular}

Table 2 Summary of Oromo clausal embedding strategies

Owens (1985) notes of Harar Oromo that some verbs are compatible with verbal nominalizations both with and without subjects (and akka clauses). Underscoring the semantic significance of the distinction between the clausal categories, we find that the choice of complement type in such cases determines the meaning of the sentence. This is illustrated in (5) with irran fad- 'forget': what was forgotten in (5a) was the occurrence of some situation, whereas in (5b) it was an intended action.
a. [kitaaba k'ara'-uu xiyya $]=$ n irran fad-d'-e [book read-NMLZ poss.1s]=1s forget-1s-PFV
'I forgot that I read the book'
b. in-ni [foon bit-uu ] irran fat-Ø-e $3 \mathrm{sm}-\mathrm{NOM}$ [meat buy-NMLZ] forget-3sm-PFV 'He forgot to buy meat.'
(Harar, Owens 1985: 158(93))

Taking stock, Oromo distinguishes three categories of embedded clauses, the distribution of which is summarized in Table 2. As the table shows, the verbal groupings found in Oromo fall along different semantic lines than those reported by Wurmbrand and Lohninger (submitted). Nevertheless, we propose that Oromo complement categories exhibit the same three-way structural hierarchy: the largest strategy, found only with verbs of speech, minimally extend into the C-domain; the middle strategy, found with attitude and other-manipulation verbs, comprises a category in the T-domain; and the smallest strategy, found with self-inducement verbs, maxes out in the $\mathrm{V}$-domain. We also adopt the view that the $\mathrm{C}$-, $\mathrm{T}$-, and $\mathrm{V}$ domains respectively map to propositions, situations, and events in the semantics. 
Situation Types in Complementation

What we find in Oromo is thus a system in which non-speech attitude verbs compose with complements that supply situations rather than propositions to the semantics. This pushes us toward a formal analysis according to which the "propositional part" of a propositional attitude is instead lexicalized in the verb. In other words, Oromo attitude reports fall at the opposite end of the typological spectrum as nisin reports in Navajo, such that the embedding verb, and not the embedded clause, does the semantic heavy-lifting. Before we lay out what such an analysis might look like, we want to first better motivate the claim that Oromo attitudes embed situations by taking a closer look at the two embedding strategies that show up in attitude reports.

\section{Structure of Oromo attitude complements}

This section treats the structure of the two embedding strategies found in Oromo attitude reports, beginning with VNS before turning to akka embedding. ${ }^{6}$ Looking ahead, we will argue that both strategies consist of a projection of the T-domain nested under a nominal projection, resulting in a definite description of a situation in the case of VNS, and in a property of situations in the case of akka embedding.

\subsection{Verbal Nominalization with Subject}

Oromo verbal nominalizations are distinguished by affixation of $-u u$ to a verbal head. As examples (6) and (7) show, verbal nominalizations with subjects contain a categorically verbal core, permitting projection of the complete array of verbal arguments as well as adverbial modifiers (here, the temporal modifiers kaleesa 'yesterday' and bor 'tomorrow'). Verbal constituents appear to the left of the verbal head, consistent with the word order observed in matrix clauses.

$$
\begin{array}{llll}
\text { [gammachuu-n } & \text { burtukana } & \text { kaleesa } & \text { nyaacc-uu=saa] } \\
\text { [Gam.-NOM } & \text { orange } & \text { yesterday } & \text { eat-NMLZ=POSS.3sm] }
\end{array}
$$

'Gammachuu's eating an orange yesterday'

$\begin{array}{lll}\text { [bor wallaggaan deem-uu=saa } & \text { beek-n-a } \\ \text { [tomorrow Wollega go-NMLZ=POSS.3sm] know-1pl-IPFV } \\ \text { 'We know his going to Wollega tomorrow', }\end{array}$

'We know his going to Wollega tomorrow.' (Wollega, Gragg 1976:193)

Compatibility with temporal specification reveals that the nominalized clauses minimally contain verbal projections belonging to the T-domain. On the other hand, nominalized verbs are not inflected for subject agreement, and aspectual

6 Detailed descriptions of both strategies can be found in Owens 1985, Alemaheyu 2015, and Mazengia 2015. 
distinctions are neutralized, suggesting that the embedded T-domain is structurally deficient. In line with this, we observe in (8) that negative verbal inflection is likewise inadmissible; negation is instead expressed with a negative verbal root.

a. takkaa-n ra'e-ttii hin gurgur-n-e

Tekka-NOM goat-SG NEG sell-NEG-PFV

'Tekka did not sell the she-goat.'

b. takkaa-n ra'e-ttii gurgur-uu baacc-uu 'isaa

Tekka-NOM goat-SG sell-NMLZ fail-NMLZ POSS.3sm

'Tekka's not selling the she-goat' (Harar, Mazengia 2015: 222)

In place of inflectional morphology we find the suffix -uu, indicative of dominance by a categorically nominal head. The categorical shift is apparent in the licensing of a (resumptive) genitive subject and case marking (see example (9)). Both appear to the right of the nominal suffix, consistent with the word order of underived nominals. Incompatibility with number morphology and demonstratives (Owens 1985; Mazengia 2015) shows that the nominalizing category is DP.

$$
\begin{array}{lll}
{\left[\begin{array}{ll}
\text { an-i } & \text { deem-uu-n=koo }
\end{array}\right.} & \text { abdii aar-s-Ø-e } \\
\text { [1s-NOM go-NMLZ-NOM=POSS.1s] } & \text { Abdi annoy-CS-3sm-IPFV } \\
\text { 'My going annoyed Abdi.' } & \text { (Tuulama, Alemayehu 2015: 31(29b)) }
\end{array}
$$

The distribution of VNS clauses is identical to that of underived nominals. Most importantly, these nominalizations can function as sentential subjects, in which case they are marked with nominative case, as in (9) above. While Oromo lacks definite determiners, ${ }^{7}$ nominative case marking is compatible only with definite subjects, i.e., subjects the referents of which are discourse familiar, or else uniquely identifiable in the context of utterance (Hodson \& Walker 1922; Owens 1985; Kebede 1989; Clamons, Mulkern \& Sanders 1993). Hence, examples like (9) show that verbal nominalizations with subjects are definite DPs.

We argue that verbal nominalizations with subjects are definite descriptions of situations, or particular eventualities. Recall that these nominalizations contain a verbal category belonging to the T-domain, which we take to correspond to situations in the semantics. Crucially, it is not the case that nominalization can apply to any old clause, in particular not those headed by the particle copula $=d h a$, as

7 The suffixes -cha (m) and -ttii (f), which can appear with select nouns in Oromo (Owens 1985), are sometimes identified as definite determiners (e.g., Nigussie 2007). However, Baye $(1986,1987)$, Kebede (1989), and Mazengia (2015) instead analyze these morphemes as singular markers, while Rijkhoff (2008) proposes that they mark predicates denoting singleton sets. Alternatively, these suffixes might be identified with what Schwarz (2009) dubs "weak" definite determiners, which require contextual uniqueness but not discourse-familiarity. What matters here is that Oromo lacks "strong" definite determiners that encode familiarity. 
captured in (10): a verbal copula like $t a$ '- 'be(come)' must be used instead. Though perhaps unsurprising, we take this selectional restriction to follow from the fact that $=d h a$ constructions involve individual-level predication and, hence, do not specify a situation. That is, provision of a situation is central to the semantics of VNS.

$$
\begin{aligned}
& \text { a. an- } \mathrm{i} \quad \text { jaamaa }=\text { dha } \\
& \text { 1s-NOM blind.m }=\mathrm{COP}_{1} \\
& \text { 'I am blind.' } \\
& \text { b. * an- } \mathrm{i} \quad \text { jaamaa }=\text { dha }-\mathrm{uu}=\mathrm{koo} \\
& \text { c. an-i jaamaa ta'-uu=koo } \\
& \text { 1s-NOM blind.m become-NMLZ=POSS.1s } \\
& \text { 'my being blind' }
\end{aligned}
$$

As additional evidence that VNS derives a definite description of situations rather than propositions, observe in (11) that VNS expresses the topic of nouns like oduu 'news' rather than the content, which is instead expressed with a full CP as in (12). ${ }^{8}$
oduu-n [leenc'a ajjees-uu takkaa] dhugaa news-NOM [lion kill-NMLZ Tekka.GEN] true
'The news of Tekka's killing a lion is true.' (Harar, Mazengia 2015: 232)

$\begin{array}{llllll}\text { oduu-cha-i } & \text { [[dachaasaa-n } & \text { burtukana } & \text { nyaat- } Ø \text {-e }] & \text { jedh-u }] & \text { sun } \\ \text { news-SG-NOM } & {[[\text { Dac.-NOM }} & \text { orange } & \text { eat-Ø-PFV }] & \text { say-DEP }] & \text { DIST }\end{array}$
'that rumor that Dachaasaa ate an orange'

\subsection{Akka construction}

We now turn to the $a k k a$ embedding strategy. As captured in example (13), akka embedding is like VNS in admitting the full array of verbal arguments as well as adverbial modifiers, all of which appear to the left of the verbal head. Unlike nominalized verbs, however, verbs embedded under akka are inflected for subject agreement and aspect. They may also inflect for negation, as in (14). ${ }^{9}$
[akka abdii-n boru ambo deem-Ø-u]
[as Abdi-NOM tomorrow Ambo go-3sm-DEP]
'that Abdi will go to Ambo tomorrow' (Tuulama, Alemaheyu 2015: 17(3a))

8 While space precludes discussion of the structure in (12), we believe it involves a relative clause structure that itself contains an embedded propositional complement. Compare to example (22).

9 As the translation of (14) indicates, negative $a k k a$ clauses are ambiguous between perfective and imperfective interpretations. This is not so for matrix clauses, where negation in the imperfective is instead expressed with hin + dependent imperfective morphology (Owens 1985; Alemaheyu 2015). 
Bryant and Bhadra

(14) [akka meetii-n hin barat-n-e]

[as Meti-NOM NEG learn-NEG-PFV]

'that Meti did/does not learn' (Tuulama, Alemaheyu 2015: 28(21b))

Existing descriptions and structural analyses (e.g., Gragg 1976; Owens 1985; Crass \& Meyer 2008; Alemaheyu 2015) treat $a k k a$ constructions as full CPs, with $a k k a$ serving as a finite complementizer on par with English that. However, there are several reasons to call this kind of analysis into question.

With respect to the assumption that $a k k a$ constructions are full CPs, we first highlight the fact that akka embedding contributes the same meaning to attitude reports (as well as other complementation contexts) as does VNS. The simplest explanation for this is that these two embedding strategies contribute the same sort of semantic object to the composition of attitude reports. Consistent with this idea, observe in (15) that akka constructions pattern with verbal nominalizations in disallowing embedding of the particle copula $=d h a$; a verbal copula must be used instead. On the other hand, =dha can be embedded in the clausal complements of speech verbs, as in (16), confirming that the unacceptability of (15a) does not follow from a more general constraint of Oromo embedding. Rather, just as in the case of VNS, we argue that this restriction follows from the fact that clauses embedded under akka must contribute a situation to the semantics.
a. *an-i [akka caaltuu-n jaamtuu=dha] aman-Ø-a
1s-NOM [as Cal.-NOM blind.f=COP] believe-1s-PFV
b. an-i [akka caaltuu-n jaamtuu ta'-ti-e]-tti
1s-NOM [as Cal.-NOM blind.f become-3sf-PFV]-LOC
aman-Ø-a
believe-1s-IPFV
'I believe that Caaltuu is blind.'
(16) an-i [caaltuu-n jaamtuu=dha] jedh- $\emptyset$-a
1s-NOM [Cal.-NOM blind.f $=\mathrm{COP}]$ say-1s-PFV
'I said that Caltuu is blind.'

Due to their comparable meaning contributions across embedding contexts and parallel selectional requirements captured in (10) and (15), we propose that the VNS and $a k k a$ embedding strategies belongs to the same complementation category, namely situation. Therefore, following Wurmbrand and Lohninger's (submitted) model of complementation, we tentatively conclude that akka constructions likewise do not project a C-domain. ${ }^{10}$

10 More precisely, we propose that $a k k a$ constructions minimally contain projections of the T-domain and crucially lack the C-domain projection responsible for the semantic transition from situations 
If this analysis is on the right track, then $a k k a$ cannot be a finite complementizer. Indeed, Dryer (2007) observes that akka is typologically exceptional in appearing non-adjacent to the complement-taking verb. What's more, akka appears in a whole host of contexts outside of clausal complementation. These contexts include predicative and restrictive similative adjectives as in (17), degree comparison as in (18), root and subject-oriented manner adverbials as in (19), speaker-oriented adverbials as in (20), and temporal adverbials as in (21).

$$
\begin{aligned}
& \text { a. foot'a-n kun [akka uffata k'orraa]=ti } \\
& \text { scarf-NOM PROX.NOM [as clothing cold] }=\mathrm{COP}_{2} \\
& \text { 'This scarf is like a blanket.' } \\
& \text { b. in-ni [akka jabaa] sun } \\
& \text { 3sm-NOM [as strong] DIST.NOM } \\
& \text { 'he (who is) like a grown-up' }
\end{aligned}
$$
b. in-ni [akka jabaa] sun
3sm-NOM [as strong] DIST.NOM

(18) ishee-n [akka isaani] d'eer-tuu

3sf-NOM [as POSS.3p] tall-f

'She is as tall as them.'

(Harar, Owens 1985: 233(1))

(19) a. dachaasaa-n [akka gaarii]-tti raf-Ø-e

Dac.-NOM [as good]-LOC sleep-3sm-PFV

'Dachaasaa slept well.'

b. gammachuu-n [akka dachaasaa]-tti fiig- $\varnothing-\mathrm{a}$

Gam.-NOM [as Dac.]-LOC run-3sm-IPFV

'Gammachuu runs like Dachaasaa.'

$\begin{array}{lllll}\text { c. gammachuu-n } & \text { [akka-uma } & \text { dachaasaa]-tti } & \text { saffisaa-n } & \text { fiig- } Ø \text {-a } \\ \text { Gam.-NOM } & \text { [as-EMPH } & \text { Dac.]-LOC } & \text { speed-INST } & \text { run-3sm-IPFV }\end{array}$

'Gammachuu runs as fast as Dachaasaa.'

(20) [akka dachaasaa]-tti gammachuu-n raf-aa jir-Ø-a

[as Dac.]-LOC Gam.-NOM sleep-CVB exist-3sm-IPFV

'(Speaking) as Dachaasaa, Gammachuu is sleeping.'

[akka Tulluu-n deem-Ø-ee] Fayyiisaa-n dhuf-Ø-e

[as Tul.-NOM go-3sm-PFV] Fay.-NOM come-3sm-PFV

'As (soon as) Tulluu went, Fayyiisaa came.' $\quad$ (Baye 1986: 60(34b))

to propositions (what we refer to as FinP in Section 4.2). According to Wurmbrand and Lohninger (submitted), a situation complement may project a syntactic $\mathrm{C}$-domain without incurring a change in meaning as long as it lacks this transitional operator. Additional data is needed to determine whether $a k k a$ constructions truly lack a C-domain, or whether they are compatible with some peripheral operators. 
Across all of these different constructions, akka carries a similative flavor. Example (21), in which akka embeds a clause, is especially informative to the present account since this construction asserts the similarity of two situations, in particular with respect to their times of occurrence. This example thus lends additional support to our claim that $a k k a$ clausal constructions contribute situations to the semantics rather than propositions. Also informative is observation of one place where $a k k a$ does not show up, namely in the expression of propositional content. We have seen one example already in (12). Consider also example (22), which shows that $a k k a$ is not used in the expression of propositional content and that verbs that embed akka (in this case, dhaga'- 'hear') do not directly embed nouns denoting contentful objects; unmarked clausal coordination is used instead to capture that a rumor (literally, the telling of a rumor) was overheard.

$$
\begin{aligned}
& \text { [[dachaasaa-n burtukana nyat-Ø-eera] oduu jet-tu-a] } \\
& \text { [[Dac.-NOM orange eat-3sm-PFV] news say-2pl-IPFV] } \\
& \text { [gammachuu-n dhaga'-Ø-eera] } \\
& \text { [Gam.-NOM hear-3sm-PFV] }
\end{aligned}
$$

In addition to illustrating akka's relational function, examples (17)-(21) also reveal that $a k k a$ is syntactically nominal. First, akka appears to the left of its constituents, consistent with the default word order of the Oromo nominal domain. Second, though it is not always morphologically apparent (cf. Owens 1985; Mazengia 2015), example (18) shows clearly that entity-denoting internal arguments of akka receive genitive case. Third, we see in (19) that akka is compatible with -uma 'very/exactly', an emphasis marker found with nouns and pronouns (Gragg 1976; Gragg \& Michigan State University 1982). And finally, as shown in (23), akka is also compatible with demonstratives like kana 'this'.

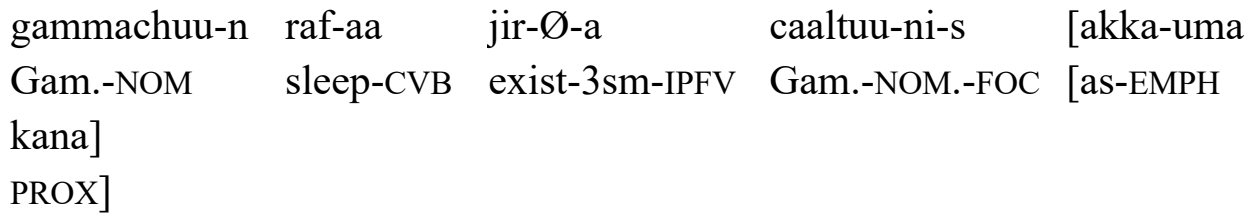

In short, contrary to the take in previous literature, we find that akka constructions do not contain a C-domain, and that $a k k a$ is (in most cases, at least) not a finite complementizer. It is of course possible to account for the various functions of akka by appealing to polysemy: such a stance is adopted by Treis (2017), who discusses $a k k a$ along with other morphemes found in languages spoken in Ethiopia and surrounding areas that exhibit some or all of the functions presented above. However, an account that assumes polysemy fails to capture the common 
Situation Types in Complementation

similative flavor found across the contexts in which $a k k a$ is deployed. Here we instead pursue a unified analysis according to which akka is in all cases a nominal head denoting a similative relation - even in attitude reports!

Before moving to a semantic analysis that can capture the empirical facts laid out so far, we want to first highlight one key difference between akka embedding and VNS. We have argued that both embedding strategies comprise the same clausal category: both minimally contain verbal projections in the T-domain (briefly, $\mathrm{TP}^{11}$ ), and both contribute situations to the semantics. However, whereas verbal nominalizations are definite DPs, akka constructions are property-denoting NPs. This difference is captured in the contrast in (24): unlike verbal nominalizations with subjects, akka constructions cannot serve as external arguments (Owens 1985; Baye 1986; Alemaheyu 2015; Mazengia 2015).

$$
\begin{aligned}
& \text { a. *[akka Tulluu-n dhuf-Ø-e] na aar-s-Ø-e } \\
& \text { [as Tul.-NOM come-3sm-PFV] 1s-NOM annoy-CAUS-1s-IPFV } \\
& \text { Intended: 'That Tulluu came annoyed me.' (Baye 1986: 201(3)) } \\
& \text { b. [an-i deem-uu-n=koo] abdii aar-s-Ø-e } \\
& \text { [1s-NOM go-NMLZ-NOM=POSS.1s] Abdi annoy-CAUS-3sm-IPFV } \\
& \text { 'My going annoyed Abdi.' }
\end{aligned}
$$

We thus arrive at the following picture: verbal nominalizations with subjects denote definite descriptions of situations (type $s$ ), while akka constructions with clausal complements denote similative relations ranging over situations (type $<s t>$ ). In the next section, we propose a semantic analysis that integrates these findings into the composition of attitude reports.

\section{A formal account for Oromo attitude reports}

\subsection{Refining the framework: types vs. tokens}

In laying out the interface framework adopted in this work, we defined situations as individual eventualities that crucially lack modal specification. That is, situations are abstract individuals. We are thus treating the semantic object corresponding to the T-domain as a type of eventuality, rather than a token.

In this way, this work builds upon the insights of recent work on event kinds, which motivates an ontological distinction between types and tokens in the verbal domain (Landman \& Morzycki 2003; Gehrke 2012; Gehrke and McNally 2015;

11 While we use 'TP' as a convenient label for the verbal categories of both VNS and akka embedding, note that VNS may in fact target a lower projection of the T-domain, for instance AspP. Crucially, we assume that all projections of the T-domain are of the same semantic type, namely $<$ st $>$, such that this distinction is irrelevant to the semantic analysis to follow. 
Grimm and McNally 2015; i.a.). Of particular relevance to the current project is Grimm and McNally's (2015) proposal that English verbal gerunds - gerunds that admit adverbial modification and assignment of accusative case, much like Oromo verbal nominalizations with subjects - denote descriptions of event kinds, there defined as abstract categories of eventualities that may be realized by token eventualities occurring in diverse times and locations. This is illustrated in (25), adapted from Grimm and McNally's example (23).

(25) Jim's raking the leaves

[[DP [DP Jim's] [D' $\varnothing[$ poss'] [vp raking the leaves ]]] $]=$ $\lambda \mathrm{e}_{\mathrm{k}}\left[\operatorname{Uraking}\left(\mathrm{e}_{\mathrm{k}}\right) \wedge \operatorname{Theme}\left(\mathbf{l}, \mathrm{e}_{\mathrm{k}}\right) \wedge \operatorname{Agent}\left(\mathbf{j}, \mathrm{e}_{\mathrm{k}}\right)\right]$

Event kinds are conceptually similar in spirit to the situation types of Barwise and Perry (1983). Interestingly, Barwise and Perry appeal to situation types in part to account for attitude and perception reports, arguing that these sorts of predicates embed situation types rather than sets of possible worlds.

In the present analysis of Oromo, we follow in Grimm and McNally's footsteps in proposing that verbal nominalizations with subjects describe a type of eventuality rather than a token; similarly, we analyze $a k k a$ constructions as properties of types. We treat types as abstract individuals that may or may not correspond to tokens in the actual world; situation types, then, are abstract individuals corresponding to (actual or non-actual) token eventualities. ${ }^{12}$ To offer some preliminary motivation for this approach, consider again example (7), repeated in (26).

$$
\begin{aligned}
& \text { [bor wallaggaan deem-uu=saa } \quad \text { beek-n-a } \\
& \text { [tomorrow Wollega go-NMLZ=POSS.3sm] know-1pl-IPFV } \\
& \text { 'We know his going to Wollega tomorrow.' }
\end{aligned}
$$

The verbal nominalization contained in this example picks out an eventuality (some salient male's going to Wollega) that has not, at the time of utterance, transpired. And yet, because the nominalization is definite, its referent must be discoursefamiliar and, hence, must exist in some sense prior to the time of utterance. The referent of the nominalization must therefore be a type, which may exist in the discourse (and, hence, in the minds of the interlocutors ${ }^{13}$ ) regardless of whether it is realized by a token in the actual world at the time of utterance.

12 In this way, the type/token distinction is notionally equivalent to the intensional/extensional distinction. We leave it to future work to explore the extent to which a more conventional intensional semantics is likewise able to capture the structural facts of Oromo.

13 We leave it open whether types ought to be understood as abstract semantic objects (e.g., Carnap 1947; Montague 1974) or as mental representations (e.g., McNally 2014; Ramchand 2018). It seems to us that both perspectives capture something true about types in natural language. 
Situation Types in Complementation

The type-token distinction will play a central role in our analysis of Oromo attitude reports. As we will show, appeal to types allows us to correctly capture the entailments that arise from the assertion of an attitude.

\subsection{Deriving Oromo attitude reports}

The evidence presented in Section 3 led us to conclude that Oromo verbal nominalizations with subjects are definite descriptions of situations while akka constructions are similative relations ranging over situations, where situations are to be understood as types of eventualities. In this section, we present a compositional account for Oromo attitude reports, first deriving the embedding strategies before proposing a situation-based semantics for Oromo attitude verbs.

We have argued that both verbal nominalizations with subjects and $a k k a$ constructions comprise TPs nested within a nominal category. For the TP embedded in (1) and (2) -Dachaasaan rafaa jiraat- 'Dachaasaa's being asleep' and Dachaasaan rafaa jiru 'Dachaasaa is sleeping'-we adopt the highly simplified denotation in (27).

$\llbracket[$ тр Dachaasaan rafaa jiraat-/jiru $] \rrbracket=\lambda \mathrm{s} . \exists \mathrm{e} .[\mathrm{R}(\mathrm{s}, \mathrm{e}) \wedge \operatorname{sleep}(\mathrm{e}) \wedge \operatorname{Ag}(\mathrm{e}, \mathrm{d})]$ where $e$ is a category of eventualities provided by the $\mathrm{V}$-domain and $\mathrm{R}$ is a relation that holds of a category $e$ and situation $s$ iff all atomic members of $s$ belong to $e$.

In full finite CPs, the property of situations denoted by TP serves as the internal argument of a finite $C$ head, Fin. Defined as in (28) below, Fin returns a property of propositions, the contents of which are true of worlds in which at least one of the situations picked out by TP correspond to an actual token.

$$
\begin{aligned}
& \llbracket[\mathrm{c} \text { Fin }] \rrbracket=\lambda \mathrm{P}<\mathrm{st}>. \lambda \mathrm{p} . \exists \mathrm{s} . \forall \mathrm{w} .[\mathrm{w} \in \operatorname{CONTENT}(\mathrm{p}) \rightarrow \mathscr{R}(\mathrm{w}, \mathrm{s}) \& \mathrm{P}(\mathrm{s})] \\
& \text { where } \mathscr{R} \text { is a relation that holds of a world } w \text { and situation } s \text { iff } w \text { contains a } \\
& \text { token eventuality } s^{*} \text { that realizes } s \text {. }
\end{aligned}
$$

It is only with the introduction of Fin into the clausal derivation that worldly particulars enter the picture. It is also at this stage that the clause may be linked to a speaker and discourse context. Crucially, we argue that FinP, a projection of the C-domain, is absent from the two complementation strategies found in Oromo attitude reports.

In nominalizations, the TP composes with a null definite determiner $\Delta$ (cf. Adger \& Quer 2001; Kastner 2015) that selects a property of situations (type $<s t>$ ) and returns an individual for which the property holds. As shown in (29), the specifier of $\Delta$ contains a contextually-supplied index that enforces identity between the individual supplied by $\Delta$ and an existing discourse referent. Verbal 
nominalizations with subjects are thus individual denoting (type $s$ ), and their referent must be discourse-familiar, as shown in (30). (We ignore the genitive subject, which we assume to be semantically inert.)

$\llbracket[\mathrm{D} \Delta] \rrbracket=\lambda \mathrm{P}_{<\mathrm{s} t>} . \lambda \mathrm{n} . \mathrm{ss}: \mathrm{P}(\mathrm{s}) \wedge \mathrm{s}=\mathrm{g}(\mathrm{n})$

where $n$ is a natural number mapping to a coordinate in the assignment function $(g)$.

【[DP [7] [D, $\Delta[$ TP Dachaasaan rafaa jiraccuu $]]]=$

is: $\exists$ e. $[\mathrm{R}(\mathrm{s}, \mathrm{e}) \wedge \operatorname{sleep}(\mathrm{e}) \wedge \operatorname{Ag}(\mathrm{e}, \mathrm{d}) \wedge \mathrm{s}=\mathrm{g}(7)]$

Paraphrase: 'the situation $s$ that exemplifies Dachaasaa sleeping and is identical to the discourse referent picked out by $\mathrm{g}(7)$ '

In $a k k a$ constructions, we see no sign of composition with $\Delta$. Instead, the embedded TP, which denotes a set of situations, receives a non-specific/generic individual interpretation, just like other property-denoting complements of akka (cf. the examples in (17)). We model this using a variant of Chierchia's (1998) $\cap$ operator, which derives a generic individual from a property, as shown in (31).

(31) $\cap \lambda$ s. $\exists$ e. $[\mathrm{R}(\mathrm{s}, \mathrm{e}) \wedge \operatorname{sleep}(\mathrm{e}) \wedge \operatorname{Ag}(\mathrm{e}, \mathrm{d})]$

Paraphrase: 'A generic situation $s$ that exemplifies Dachaasaa sleeping'

Akka introduces a type-flexible similative operator, defined in (32). The outcome of composition with a situational complement results in a relation ranging over situations, as shown in (33).

$\llbracket[\mathrm{N}$ akka $\left.] \rrbracket=\lambda \mathrm{y}_{\sigma} \cdot \lambda \mathrm{x}_{\sigma \cdot[\mathrm{AS}}(\mathrm{x}, \mathrm{y})\right]$

where $x, y \in \mathrm{D}_{\text {IND }}$ and AS holds between $x, y$ iff $\forall \mathrm{P}_{<\sigma \mathrm{\sigma t}}$ : $\mathrm{P}$ is salient/relevant. $[\mathrm{P}(\mathrm{x}) \wedge \mathrm{P}(\mathrm{y})]$

$$
\begin{aligned}
& \mathbb{[}[\mathrm{Np}[\mathrm{N} \text { akka }][\text { те Dachaasaan rafaa jiru }]] \rrbracket= \\
& \lambda \mathrm{s}^{\prime} .[\mathrm{AS}(\mathrm{s},, \cap \lambda \mathrm{s} . \exists \mathrm{e} .[\mathrm{R}(\mathrm{s}, \mathrm{e}) \wedge \operatorname{sleep}(\mathrm{e}) \wedge \operatorname{Ag}(\mathrm{e}, \mathrm{d})])]
\end{aligned}
$$

Paraphrase: 'the set of situations $s$ ' that share all the contextually salient, relevant properties of a generic situation $s$ that exemplifies Dachaasaa sleeping'

We assume that the derivations sketched above apply for VNS and akka embedding regardless of the context in which they occur. Now, we show how these embedding strategies fit into the composition of Oromo attitude reports. We treat attitudes as eventualities with intensional content, and we define Oromo attitude verbs as three-place predicates relating a situation $s$, entity $x$, and event category $e$. This is illustrated in (34) for aman- 'believe' (cf. Hacquard 2010; Moulton 2015; Hanink \& Bochnak 2017). 
Situation Types in Complementation

$\llbracket[\mathrm{v}$ aman- $] \rrbracket=\lambda \mathrm{s} . \lambda \mathrm{x} . \lambda \mathrm{e} .[\operatorname{BEL}(\mathrm{e}) \wedge \operatorname{Exp}(\mathrm{e}, \mathrm{x}) \wedge \forall \mathrm{w} \in \operatorname{CONT}(\mathrm{e}) \cdot[\mathscr{R}(\mathrm{w}, \mathrm{s})]]$ such that $\operatorname{DOX}(\mathbf{t x}: \operatorname{Exp}(\mathrm{e}, \mathrm{x})) \subseteq \operatorname{CONTENT}(\mathrm{e})$, where $\mathscr{R}(\mathrm{w}, \mathrm{s})=1$ iff $w$ contains a token eventuality $s^{*}$ that realizes $s$

Combining elements familiar from Neo-Davidsonian event semantics and Hintikkan modal semantics, this denotation entails that if an individual $x$ is in a state of belief towards a situation $s$, then $s$ is realized by a token eventuality $s^{*}$ in all worlds belonging to the set of worlds determined by $x$ 's doxastic alternatives.

Notice that in Oromo, the attitude verb introduces the $R$-relation into the derivation; on the other hand, we argued above that this relation is not found in the verb's complement, whether encoded as a verbal nominalization or akka construction. In other words, it is the verb that does the work of introducing a proposition to the composition of attitude reports, along with modal quantification and attitude flavor. Oromo attitude verbs are thus semantically heavy, bundling all three of the key components of attitudes identified in Section 2. Conversely, their complements are semantically light: lacking a C-domain, they introduce a situation - a type of eventuality - into the semantics. This division of labor is just the opposite from what is found in nisin attitude reports in Navajo, placing Oromo attitude reports at the other end of the landscape laid out in Table 1.

To account for the compatability of Oromo attitude verbs with both VNS and $a k k a$-embedding, we propose two methods of composition. Verbal nominalizations with subjects, being of type $s$, compose with attitude verbs via Functional Application, saturating their internal argument slot. Akka constructions, being of type $<s t>$, instead compose with attitude verbs via Restrict (Chung \& Ladusaw 2004), leaving the internal argument variable open for subsequent existential closure. Continuing up the clausal spine, the examples in (35) and (36) come to have the denotations given in (37) and (38), respectively.

(35) Gammachuun Dachaasaan rafaa jiraaccuusaatti amana 'Gammachuu believes Dachaasaa is sleeping'

(36) Gammachuun akka Dachaasaan rafaa jirutti amana

'Gammachuu believes Dachaasaa is sleeping'

$\llbracket[$ FinP Gammachuun [DP Dachaasaan rafaa jiraaccuusaa]tti amana]》 $=$ $\lambda$ p. $\exists$ s, e. $\forall \mathrm{w} \in \operatorname{CON}(\mathrm{p}) .[\mathscr{R}(\mathrm{w}, \mathrm{s}) \wedge \mathrm{R}(\mathrm{s}, \mathrm{e}) \wedge \operatorname{BEL}(\mathrm{e}) \wedge \operatorname{Exp}(\mathrm{e}, \mathrm{g}) \wedge \forall \mathrm{w}, \in$ $\operatorname{CON}(\mathrm{e}) .\left[\mathscr{R}\left(w^{\prime}\right.\right.$, is': $\left.\left.\left.\exists \mathrm{e}^{\prime} .\left[\mathrm{R}\left(\mathrm{s}^{\prime}, \mathrm{e}^{\prime}\right) \wedge \operatorname{SLEEP}\left(\mathrm{e}^{\prime}\right) \wedge \operatorname{Ag}\left(\mathrm{e}^{\prime}, \mathrm{d}\right)\right] \wedge \mathrm{s}^{\prime}=\mathrm{g}(7)\right)\right]\right]$

Paraphrase: 'A set of propositions true of worlds in which Gammachuu is in a state of belief towards a familiar situation of Dachaasaa sleeping' What it entails: In all worlds compatible with what Gammachuu believes, there is a token eventuality that realizes a familiar situation (type of eventuality) of Dachaasaa sleeping. 
$\llbracket[$ FinP Gammachuun [NP akka Dachaasaan rafaa jiru $] \mathrm{tti}$ amana $] \rrbracket=$ $\lambda$ p. $\exists$ s, e, s'. $\forall \mathrm{w} \in \mathrm{CON}(\mathrm{p}) .\left[\mathscr{R}(\mathrm{w}, \mathrm{s}) \wedge \mathrm{R}(\mathrm{s}, \mathrm{e}) \wedge \operatorname{BEL}(\mathrm{e}) \wedge \operatorname{Exp}(\mathrm{e}, \mathrm{g}) \wedge \forall \mathrm{w}^{\prime} \in\right.$ $\left.\operatorname{CON}(\mathrm{e}) .\left[\mathscr{R}\left(\mathrm{w}^{\prime}, \mathrm{s}^{\prime}\right) \wedge \operatorname{AS}\left(\mathrm{s}^{\prime}, \cap \lambda \mathrm{s}^{\prime}, . \exists \mathrm{e}^{\prime} .\left[\mathrm{R}\left(\mathrm{s}^{\prime},, \mathrm{e}^{\prime}\right) \wedge \operatorname{SLEEP}\left(\mathrm{e}^{\prime}\right) \wedge \operatorname{Ag}\left(\mathrm{e}^{\prime}, \mathrm{d}\right)\right]\right)\right]\right]$ Paraphrase: 'A set of propositions true of worlds in which Gammachuu is in a state of belief towards a situation with all the salient/relevant features of a generic situation of Dachaasaa sleeping'

What it entails: There exists a situation (type of eventuality) of Dachaasaa sleeping such that, in all worlds compatible with what Gammachuu believes, there is a token eventuality that realizes that situation.

While truth-conditionally comparable, the two embedding strategies found in Oromo attitude reports are thus crucially distinct with respect to the constraints they impose on the discourses in which they occur. Verbal nominalizations are definite DPs: they require identity with a salient discourse antecedent and, therefore, are felicitous only when their referent is discourse-familiar. Akka constructions, on the other hand, carry no such familiarity condition: TPs embedded under $a k k a$ receive a generic individual interpretation. The $a k k a$ embedding strategy is therefore used whenever the conditions for VNS are not satisfied. Selection between strategies hence depends (at least in part) on definiteness. Note that this is true for both factive and non-factive verbs, revealing that factivity per se does not determine the distribution of embedding strategies in Oromo. ${ }^{14}$

\section{Conclusion}

In this paper, we have argued that Oromo exemplifies a system of embedding in which attitudes are uniformly expressed towards situations rather than propositions, and we have sketched a formal account of Oromo attitude reports that captures the distribution of the complementation strategies that appear with attitudes, the selectional restrictions and discourse constraints imposed by those strategies, and the wider distribution of akka. This analysis paves the way for expansion of the empirical landscape of attitudes in two ways:

- Situations and propositions are both ontological primitives used by languages in the construction of attitude reports.

- Attitude verbs in languages like Oromo do all the semantic heavy lifting, contributing a proposition, modal quantification, and attitude flavor to the composition, thus filling out the logical space of ways in which these components can be encoded in natural language.

14 Oromo is in this property similar to languages like Korean (Bogal-Allbritten \& Moulton 2017), in contrast with languages like Hebrew (Kastner 2015) and Washo (Hanink \& Bochnak 2017). 
Situation Types in Complementation

\section{References}

Adger, David \& Josep Quer. 2001. The syntax and semantics of unselected embedded questions. Language 77(1). 107-133. doi: 10.1353/lan.2001.0001

Alemayehu, Hawine. 2007. The structures of nominal clauses in Afan Oromo: a minimalist approach. Addis Ababa University $\mathrm{PhD}$ dissertation.

Barwise, Jon \& John Perry. 1983. Situations and Attitudes. Cambridge, MA: MIT Press.

Baye, Yimam. 1986. The phrase structures of Ethiopian Oromo. School of Oriental and African Studies PhD Dissertation.

Baye, Yimam. 1987. Relative Clauses in Oromo. Journal of Ethiopian Studies 20. 60-74.

Bogal-Allbritten, Elizabeth \& Keir Moulton. 2018. Nominalized Clauses and Reference to Propositional Content. In Sinn und Bedeutung (SuB), vol. 21(1), 215-232.

Bogal-Allbritten, Elizabeth. 2016. Building meaning in Navajo. University of Massachusetts at Amherst $\mathrm{PhD}$ dissertation.

Carnap, Rudolf. 1947. Meaning and necessity: A study in semantics and modal logic. Chicago, IL: University of Chicago Press.

Chierchia, Gennaro. 1998. Reference to kinds across languages. Natural Language Semantics 6(4). 339-405. doi: 10.1023/a:1008324218506

Chomsky, Noam. 1981. Lectures on Government and Binding. Dordrecht: Foris Publications.

Chomsky, Noam. 1986. Barriers. Cambridge, MA: MIT Press.

Chomsky, Noam. 1995. The Minimalist Program. Cambridge, MA: MIT Press.

Chung, Sandra \& William Ladusaw. 2004. Restriction and Saturation. Cambridge, MA: MIT Press.

Clamons, Cynthia R., Ann Mulkern \& Gerald Sanders. 1993. Salience signaling in Oromo. Journal of Pragmatics 19(6). 519-536. doi: 10.1016/03782166(93)90110-B

Crass, Joachim \& Ronny Meyer. 2008. Ethiopia. In Bernd Heine \& Derek Nurse (eds.),. A Linguistic Geography of Africa, 228-249. Cambridge: Cambridge University Press. doi: 10.1017/CBO9780511486272.008

Deal, Amy Rose. 2017. Shifty asymmetries: universals and variation in shifty indexicality. UC Berkeley manuscript.

Dryer, Matthew. 2007. Word Order. In Timothy Shopen (ed.), Language Typology and Syntactic Distinction, Vol. 1: Clause Structure, 61-131. New York, NY: Cambridge University Press.

Dubinsky, Stanley, Maria-Rosa Lloret \& Paul Newman. 1988. Lexical and syntactic causatives in Oromo. Language 64(3). 485-500. doi: 10.2307/414530 
Elliot, Patrick. 2016. Explaining DPs vs. CPs without syntax. In $52^{\text {nd }}$ annual meeting of the Chicago Linguistics Society (CLS52), 171-85.

Gehrke, Berit. 2012. Passive states. In Violeta Demonte \& Louise McNally (eds.), Telicity, Change, and State: A Cross-Categorial View of Event Structure. Oxford: Oxford University Press. doi: 10.1093/acprof:oso/9780199693498 .003 .0008

Gerhke, Berit \& Louise McNally. 2015. Distributional modification: The case of frequency adjectives. Language 19(4). 837-70. doi: 10.1353/lan.2015.0065

Givón, Talmy. 1980. The binding hierarchy and the typology of complements. Studies in Language 4(3). 333-377. doi: 10.1075/s1.4.3.03giv

Gragg, Gene. 1976. Oromo of Wellega. In Lionel Bender (ed.), The Non-Semitc Languages of Ethiopia, 166-195. East Lansing, MI: African Studies Center, Michigan State University.

Gragg, Gene \& Michigan State University. 1982. Oromo Dictionary. East Lansing, Mich.: African Studies Center, Michigan State University, in cooperation with Oriental Institute, University of Chicago.

Grimm, Scott \& Louise McNally. 2015. The -ing dynasty: Rebuilding the semantics of nominalizations. In Semantics and Linguistic Theory (SALT), vol. 25, 82-102. doi: $10.3765 /$ salt.v25i0.3070

Grohmann, Kleanthes K. 2003. Prolific domains: On the anti-locality of movement dependencies. Amsterdam: John Benjamins.

Hacquard, Valentine. 2010. On the event relativity of modal auxiliaries. Natural Language Semantics 18(1). 79-114. doi: 10.1007/s11050-010-9056-4

Hanink, Emily \& Ryan Bochnak. 2017. Factivity and two types of embedded clauses in Washo. In $47^{\text {th }}$ annual meeting of the North East Linguistic Society (NELS47), vol. 2, 65-78.

Hintikka, Jaakko. 1969. Semantics for propositional attitudes. In Models for Modalities. Selected Essays, 87-111. Dordrecht: Reidel. doi: 10.1007/978-94010-1711-4 6

Hodson, Arnold W. \& Craven H. Walker. 1922. An Elementary and Practical Grammar of the Galla or Oromo Language. London: Society for the Promotion of Christian Knowledge.

Kastner, Itimar. 2015. Factivity mirrors interpretation: The selectional requirements of presuppositional verbs. Lingua 164. 156-188. doi: 10.1016/j.lingua.2015.06.004

Kebede, Ishetu. 1989. The copula in Oromo. In Paul Newman \& Rober D. Botne (eds.), Current Approaches to African Linguistics 5, 85-93. Dordrecht: Foris.

Kratzer, Angelika. 2016. Evidential moods in attitude and speech reports (slides). $1^{\text {st }}$ Syncart Workshop, University of Siena.

Landman, Meredith \& Marcin Morzycki. 2003. Event-kinds and manner modification. In Western Conference in Linguistics (WECOL) 2002, vol. 11, 1- 
Situation Types in Complementation

12.

Mazengia, Shimelis. 2015. Nominalization via Verbal Derivation. Wiesbaden: Harrassowitz Verlag.

McNally, Louise. 2014. Kinds, descriptions of kinds, concepts, and distributions. In Kata Balogh \& Wiebke Petersen (eds.), Bridging Formal and Conceptual Semantics. Selected papers of BRIDGE-14. Düsseldorf: Düsseldorf University Press.

Montague, Richard. 1974. The proper treatment of quantification in ordinary English. In Richmond Thomason (ed.), Formal Philosophy, 247-270. New Haven, CT: Yale University Press.

Moulton, Keir. 2015. CPs: copies and compositionality. Linguistic Inquiry 46(2). 305-342. doi: 10.1162/ling a 00183

Nigussie, Yirgu. 2007. The Oromo nominal and adjectival predicates. Nairobi Evangelical Graduate School of Theology MA thesis.

Owens, Jonathan. 1985. A Grammar of Harar Oromo (Northeastern Ethiopia). Hamburg: Buske.

Platzack, Christer. 2000. Multiple interfaces. In Emile van der Zee \& Urpo Nikanne (eds.), Cognitive interfaces: Constraints on Linking Cognitive Information, 2153. Oxford: Oxford University Press.

Pollock, Jean-Yves. 1989. Verb movement, Universal Grammar, and the structure of IP. Linguistic Inquiry 20(3). 365-424.

Ramchand, Gillian \& Peter Svenonius. 2014. Deriving the functional hierarchy. Language sciences 46. 152-174. doi: 10.1016/j.langsci.2014.06.013

Ramchand, Gillian. 2018. Situations and Syntactic Structures: Rethinking Auxiliaries and Order in English. Cambridge, MA: MIT Press.

Rice, Keren. 1986. Some remarks on direct and indirect speech in Slave (Northern Athapaskan). In Florian Coulmas (ed.), Direct and Indirect Speech, 47-76. Mouton de Gruyter. doi: 10.1515/9783110871968.47

Rijkhoff, Jan. 2008. On flexible and rigid nouns. Studies in Language 32(3). $727-$ 752. doi: $10.1075 / \mathrm{sl} \cdot 32.3 .12$ rij

Schwarz, Florian. 2009. Two types of definites in natural language. MIT PhD Dissertation.

Sundaresan, Sandhya. 2011. A plea for syntax and a return to first principles: monstrous agreement in Tamil. In Semantics and Linguistic Theory (SALT), vol. 21, 674-693. doi: $10.3765 /$ salt.v0i0.2626

Sundaresan, Sandhya. 2012. Context and (co)reference in the syntax and its interfaces. Universität Stuttgart $\mathrm{PhD}$ Dissertation.

Treis, Yvonne. 2017. Similative morphemes as purpose clause markers in Ethiopia and beyond. In Yvonne Treis and Martine Vanhove (eds.), Similative and Equative Constructions: A cross-linguistic perspective, 91-142. Amsterdam: John Benjamins. doi: 10.1075/tsl.117.05tre 
Wurmbrand, Susi and Magdalena Lohninger. submitted. An implicational universal in complementation: Theoretical insights and empirical progress. In Jutta M. Hartmann and Angelika Wöllstein (eds.), Propositional Arguments in CrossLinguistics Research: Theoretical and Empirical Issues. Tübingen: Gunter Narr Verlag. lingbuzz/004550

Shannon Bryant

Boylston Hall

Harvard University

Cambridge, MA 02138

sgbryant@g.harvard.edu
Diti Bhadra

S313 Elliot Hall

University of Minnesota

Minneapolis, MN 55455

bhadra@umn.edu 